\title{
SPARC functions as an inhibitor of adipogenesis
}

\author{
Jing Nie $\cdot$ E. Helene Sage
}

Received: 23 June 2009 / Accepted: 26 August 2009 / Published online: 2 October 2009

(C) The Author(s) 2009. This article is published with open access at Springerlink.com

\begin{abstract}
Adipogenesis, a key step in the pathogenesis of obesity, involves extensive ECM remodeling, changes in cell-ECM interactions, and cytoskeletal rearrangement. Matricellular proteins regulate cell-cell and cell-ECM interactions. Evidence in vivo and in vitro indicates that the prototypic matricellular protein, SPARC, inhibits adipogenesis and promotes osteoblastogenesis. Herein we discuss mechanisms underlying the inhibitory effect of SPARC on adipogenesis. SPARC enhances the $\mathrm{Wnt} / \beta$ catenin signaling pathway and regulates the expression and posttranslational modification of collagen. SPARC might drive preadipocytes away from the status of growth arrest and therefore prevent terminal differentiation. SPARC could also decrease WAT deposition through its negative effects on angiogenesis. Therefore, several stages of white adipose tissue accumulation are sensitive to the inhibitory effects of SPARC.
\end{abstract}

Keywords SPARC · Adipocyte - Obesity · Collagen ·

$\mathrm{Wnt} \cdot \beta$-catenin $\cdot$ Angiogenesis

$\begin{array}{ll}\text { Abbreviations } \\ \text { BM } & \text { basement membrane } \\ \text { C/EBP } & \text { CAAT/enhancer-binding protein } \\ \text { ECM } & \text { extracellular matrix } \\ \text { FN } & \text { fibronectin } \\ \text { GSK } & \text { glycogen synthase kinase } \\ \text { ILK } & \text { integrin-linked kinase }\end{array}$

J. Nie $(\square) \cdot$ E. H. Sage

Hope Heart Program,

Benaroya Research Institute at Virginia Mason,

1201 9th Ave,

Seattle, WA 98101, USA

e-mail: jnie@benaroyaresearch.org

$\begin{array}{ll}\text { LN } & \text { laminin } \\ \text { MSC } & \text { mesenchymal stem cell } \\ \text { PDGF } & \text { platelet-derived growth factor } \\ \text { PPAR } & \text { peroxisome proliferator-activated receptor } \\ \text { SPARC } & \text { secreted protein acidic and rich in cysteine } \\ \text { TGF } & \text { transforming growth factor } \\ \text { TCF/LEF } & \text { T-cell factor/lymphoid-enhancing factor } \\ \text { VEGF } & \text { vascular endothelial growth factor } \\ \text { WAT } & \text { white adipose tissue }\end{array}$

\section{Introduction}

Obesity, an energy balance disorder represented as excessive accumulation of white adipose tissue (WAT), is a major public health problem in developed countries. The cellular composition of WAT includes primarily adipocytes and preadipocytes, as well as endothelial cells and macrophages. Obesity is the result of increases in cell size (adipocyte hypertrophy) and cell number. Adipocytes are not only the storage depots of energy, but also the source of various cytokines and hormones. These so-called adipokines, e.g., tumor necrosis factor- $\alpha$, leptin, adiponectin, and resistin, target the central nervous system and peripheral tissues (WAT, liver and muscle) to modulate energy metabolism (Gregoire et al. 1998; Rosen and Spiegelman 2000).

Adipocytes are derived from multipotent mesenchymal stem cells (MSC). The first phase of adipogenesis is fate determination, which involves the conversion of MSCs to preadipocytes. The second phase, known as terminal differentiation, is the process by which preadipocytes differentiate into adipocytes. Many studies have defined mechanisms by which transcription factors and hormones regulate terminal differentiation in cultured 3T3-L1/F442 
cells. Terminal differentiation involves a cascade of transcriptional regulation. The first step is induction of the expression and activation of CAAT/enhancer-binding protein $\beta$ $(\mathrm{C} / \mathrm{EBP} \beta)$ and $\mathrm{C} / \mathrm{EBP} \delta$, which, in turn, induce the expression of $\mathrm{C} / \mathrm{EBP} \alpha$ and peroxisome proliferator-activated receptor $\gamma$ (PPAR $\gamma)$, the central transcriptional regulators for adipogenesis. A variety of signaling pathways regulate adipogenesis, including transforming growth factor (TGF)- $\beta$, tumor necrosis factor- $\alpha$, Wnt, insulin/ insulin-like growth factor-1, and other growth factors.

Extracellular matrix (ECM) is crucial for tissue and organ development; however, it has not received sufficient attention in adipose tissue because of its apparent paucity (due to the minimal space ECM could occupy) and the difficulties associated with analysis of ECM components. The main constituents of ECM in WAT are collagen (types I, IV, and $\mathrm{VI})$, laminin $(\mathrm{LN}-1,8)$, fibronectin $(\mathrm{FN})$, hyaluronan, and proteoglycans (Khan et al. 2009; Wilsie et al. 2005). Adipogenesis involves extensive ECM remodeling, changes in cell-ECM adhesion, and cytoskeletal rearrangement. Cell-associated ECM switches from a FN-enriched matrix into basement membrane (BM). ECM components have major effects on preadipocyte differentiation. For example, FN inhibits adipogenesis, whereas LN and type IV collagen enhance adipogenesis, in two-dimensional cell culture (O'Connor et al. 2003; Rodriguez Fernandez and Ben-Ze'ev 1989; Spiegelman and Ginty 1983).

Matricellular proteins regulate cell-cell and cell-ECM interactions, and they are involved in developmental and disease/stress-induced remodeling (Bornstein and Sage 2002). These proteins interact with ECM components, as well as with cell surface receptors and growth factors, to modulate cell signaling. Secreted protein acidic and rich in cysteine (SPARC) is the first known matricellular protein linked to the 'balance' of WATs. SPARC-null mice exhibit increased accumulation of WAT (Bradshaw et al. 2003a). There are increases in both cell size and cell number in WAT of SPARC-null mice compared with that of WT mice (Bradshaw et al. 2003b). SPARC inhibits differentiation of preadipocytes (or MSCs) into adipocytes but favors that of osteoblastocytes (Delany et al. 2003; Nie and Sage 2009). SPARC is enriched in WAT, and both subcutaneous and mesenteric WATs show high levels of SPARC mRNA (Takahashi et al. 2001). Expressed in bone marrow MSCs, preadipocytes, and mature adipocytes, SPARC is enhanced at certain stages of adipogenesis (Chavey et al. 2006; Delany et al. 2003; Nie and Sage 2009). The ECM remodeling accompanying adipogenesis requires matricellular proteins, especially SPARC, to stabilize the tissue and maintain the balance of lipogenesis and lipolysis. Indeed, SPARC is significantly enhanced in obese mouse WAT (Tartare-Deckert et al. 2001). In humans, the plasma concentration of SPARC was correlated positively with body mass index (Takahashi et al. 2001). The inflammatory environment of obesity is associated with increased TGF $\beta$ (Keophiphath et al. 2009), which causes fibrosis and might increase the expression of SPARC. ECM remodeling requires SPARC to facilitate the development of mature collagen fibrils and other post-translational modifications of collagen. The inflammatory environment of obesity thereby induces fibrosis to restrain the overgrowth of WAT. However, other adipokines and metabolic regulation may override the effects of TGF $\beta$, SPARC, and collagen.

ECM remodeling requires SPARC, whereas SPARC, to some extent, can prevent hypertrophy of adipocytes and hyperplasia of adipocyte progenitors. According to the "critical fat cell size hypothesis", upon metabolic stimulation, lipid accumulates in adipocytes and cell size increases. When cell size reaches a certain threshold, signaling favors adipocyte differentiation; alternatively, preadipocyte proliferation is activated and cell number will increase. The disorganized collagen matrix in SPARC-null WAT might allow adipocytes to grow to a greater size and would eventually lead to hyperplastic WAT. Loss of SPARC expression enhances adipocyte differentiation and might improve preadipocyte proliferation. In addition, SPARC appears to regulate appetite control such that total WAT accumulation is enhanced.

\section{ECM and adipogenesis}

Adipogenesis is characterized by conversion of a FN-rich stromal ECM to a LN-rich BM; consistently, integrin expression switches from $\alpha 5$ (FN) to $\alpha 6$ (LN) (Liu et al. 2005). LN and matrigel enhance adipogenesis; FN and poly-L-lysine exert inhibitory effects on adipogenesis (Gregoire et al. 1998; Liu et al. 2005; O'Connor et al. 2003). The inhibitory activity of FN requires cell spreading, and cytochalasin $\mathrm{D}$, via its disruption of actin filaments, can overcome the inhibitory effects of FN (Spiegelman and Ginty 1983). Remodeling of ECM proteins induces changes in the cytoskeleton. FN is linked to actin stress fibers, whereas LN polymerization on the cell surface promotes the formation of a cortical actin network (Colognato et al. 1999). During adipogenesis, SPARC enhances the deposition of $\mathrm{FN}$ and the expression of its receptor, $\alpha 5$ integrin (Nie and Sage 2009). In lung fibroblasts, SPARC enhanced cell-mediated partial unfolding of FN molecules and FNinduced stress fiber formation through ILK-dependent contractile signaling (Barker et al. 2005). The unfolding of FN molecules is an important step in FN fibril formation. SPARC might also enhance this process through ILK signaling and contribute to the increased deposition of FN.

BM components support the survival and maturation of adipocytes. Injections of BM proteins, in combination with 
FGF-2, can induce de novo adipogenesis at the site of the injection (Kawaguchi et al. 1998). SPARC inhibits the expression of the LN $\alpha 1$ chain and one of its major receptors, $\alpha 6$ integrin, as well as the deposition of LN itself during adipogenesis (Nie and Sage 2009). SPARC regulates the secretion and deposition of LN in lens cells (Weaver et al. 2006). The expression of $\alpha 6$ integrin correlates with the growth-arrest of preadipocytes during adipogenesis, and it favors differentiation over proliferation of preadipocytes (Liu et al. 2005). $\alpha 6$ integrin and LN enhance adipogenesis and lipid accumulation. The interaction of LN and $\alpha 7 \beta 1$ integrin is required for basal lamina formation and actin reorganization in muscle cells (Colognato et al. 1999). Similarly, $\alpha 6$ integrin might be required for receptor-facilitated LN self-assembly, basal lamina formation, actin reorganization, and other adipogenic signaling events. Moreover, SPARC interacts with type IV collagen (Maurer et al. 1995). SPARC is required for collagen-IV-dependent stability of basal lamina in Drosophila embryos (Martinek et al. 2008). Therefore, it is likely that SPARC inhibits adipogenesis in part by interference with the formation of BM.

Collagen contributes to the support of tissues and can thereby regulate adipogenesis. In $C$. elegans, diminished expression of collagen by RNAi causes substantial reduction in fat, whereas RNAi targeting of collagen triple helical repeats increases fat content (Ashrafi et al. 2003). The predominantly-expressed collagen mRNAs in WAT encode types I, IV, and VI (Khan et al. 2009). Type I collagen forms collagen fibrils, found in the interstitial space; type IV collagen contributes to the BM, whereas type VI collagen interacts with both type I and IV collagen (Kuo et al. 1997).

In 2-dimensional cell culture, the effect of collagen fibril structure on adipocyte differentiation is minimal (O'Connor et al. 2003). However, in a 3-dimensional collagen matrix and in vivo, adipogenesis is significantly reduced $(>80 \%)$ in membrane-type 1 matrix metalloproteinase (MT1-MMP) null preadipocytes due to diminished collagen remodeling (Chun et al. 2006). There is less collagen degradation and a more dense collagen fibrillar network in WAT of MT1MMP-null mice compared with that of WT mice (Chun et al. 2006). The absence of MMP-19, which cleaves type IV collagen, enhances diet-induced obesity ( $>2$ fold) and increases adipocyte size (Pendas et al. 2004). Consistently, mice receiving a high fat diet and treated with MMP inhibitors exhibited less WAT and increased numbers of adipocytes. These data indicate that the collagen network is a barrier for adipogenesis and that collagen remodeling is required for adipocytes to grow and divide.

SPARC binds to collagen types I and IV (Hohenester et al. 2008; Maurer et al. 1995), regulates fibrillogenesis of type I, and is required for the development of mature crosslinked collagen fibrils. In the skin of SPARC-null mice, hydroxyproline content is reduced, and the collagen fibers are smaller, immature, and less crosslinked (Bradshaw et al. 2002; Bradshaw et al. 2003a). There is also less hydroxyproline in the WAT of these animals (Bradshaw et al. 2003b), and the collagen fibers appear to be less mature. The decreased collagen content and disorganized collagen network in SPARC-null mice might be more susceptible to protease degradation and remodeling, properties allowing adipocytes to grow to a greater size and contributing to hyperplastic WAT.

Type VI collagen modulates collagen fibrillogenesis, affects FN assembly, and is anchored to BM through its interaction with type IV collagen (Kuo et al. 1997; Minamitani et al. 2004; Sabatelli et al. 2001). Because WATs from collagen VI-null mice exhibit a substantially increased interstitial space among mature adipocytes, type VI collagen might serve as a link between the BM network and collagen fibrils (types I and III) (Khan et al. 2009). Type VI collagen also regulates WAT development. Collagen VI-null mice show increased adipocyte size, although the total weight of WAT is lower than that of wild-type mice (Khan et al. 2009). Because SPARC-null mice have increased levels of soluble type VI collagen in their dermis (Bradshaw et al. 2002), SPARC might affect the expression, folding, post-translational modification, and/or secretion of type VI collagen in WAT. Therefore, SPARC could regulate adipogenesis through type VI collagen.

\section{Wnt/ $\beta$-catenin and adipogenesis}

Preadipocytes enter a state of growth arrest in the G1 phase of the cell cycle prior to their terminal differentiation. SPARC inhibits preadipocyte adhesion by its interaction with integrin $\alpha 5 \beta 1$ and enhances cell migration. In melanoma cells, SPARC enhances snail activity and downregulates E-cadherin (Robert et al. 2006). If SPARC diminishes E-cadherin in preadipocytes, this change would lead to nuclear translocation and accumulation of $\beta$-catenin. Thus, preadipocytes could exit from the state of growth arrest but not be able to terminally-differentiate into adipocytes.

MSC can differentiate into a variety of tissues, including muscle, bone, cartilage, and fat. Wnt signaling, one of the key factors controlling MSC fate, inhibits adipogenesis and enhances myogenesis or osteoblastogenesis (Arango et al. 2005; Bodine et al. 2004). Constitutively-activated Frizzled (Fz) increases the stability of $\beta$-catenin, inhibits apoptosis, inhibits adipogenesis, and induces osteoblastogenesis (Kennell and MacDougald 2005). Disruption of $\mathrm{Wnt} / \beta$-catenin signaling leads to spontaneous adipocyte differentiation (Longo et al. 2004; Ross et al. 2000). Endogenous Wnts, especially Wnt10b, restrain preadipocyte differentiation (Longo et al. 2004). Activation of this pathway is sufficient to inhibit the differentiation and 
apoptosis of preadipocytes through an inhibition of $\mathrm{C} / \mathrm{EBP} \alpha$ and PPAR $\gamma$ (Farmer 2005; Ross et al. 2000). Wnt proteins bind to Fz receptors and low-density lipoprotein receptorrelated protein (LRP) coreceptors $5 / 6$ to activate several signaling pathways. Importantly, the inhibition of glycogen synthase kinase $3 \beta$ (GSK3 $\beta$ ) via Wnt results in the stabilization of $\beta$-catenin in the cytoplasm, and reduces its proteosomal degradation. After translocation to the nucleus, $\beta$-catenin binds to and coactivates transcription factors that include members of the T-cell factor/lymphoid-enhancing factor (TCF/LEF) family (Christodoulides et al. 2009).

SPARC-null mice exhibit increased accumulation of fat and a decrease in bone mass. The direction of differentiation of MSCs favors bone over fat in these animals. Recently we have shown that SPARC inhibits adipogenesis and enhances osteoblastogenesis by its enhancement of the accumulation of $\beta$-catenin ( $\mathrm{Nie}$ and Sage 2009). Both exogenous and endogenous SPARC promote the accumulation of $\beta$ catenin. During early adipogenesis, the decrease in the abundance of $\beta$-catenin coincides with the accumulation of PPAR $\gamma$ (Moldes et al. 2003). PPAR $\gamma$ can suppress Wnt signaling by its targeting of phosphorylated $\beta$-catenin to the proteasome (Girnun et al. 2002; Liu et al. 2006; Moldes et al. 2003). Conversely, $\beta$-catenin not only inhibits expression of PPAR $\gamma$, but also inhibits its transcriptional activity through a direct interaction involving its TCF/LEF binding domain (Liu et al. 2006). In addition, $\mathrm{Wnt} / \beta$-catenin enhances osteoblastogenesis through repression of the expression of $\mathrm{C} / \mathrm{EBP} \alpha$ and PPAR $\gamma$ (Kang et al. 2007). Consistently, SPARC inhibited the expression of PPAR $\gamma$ and $\mathrm{C} / \mathrm{EBP} \alpha$ at later stages of differentiation. These data provide further evidence that SPARC inhibits the key transcriptional cascades of adipogenesis through the $\mathrm{Wnt} / \beta$-catenin pathway.

The Wnt/ $\beta$-catenin pathway also plays an essential role during skeletal development. Inactivation of $\beta$-catenin in MSCs blocks osteoblast differentiation (Hartmann 2006). During postnatal development, $\beta$-catenin is also involved in osteoblast proliferation and maturation, and in osteoclastogenesis (Glass et al. 2005; Glass and Karsenty 2006). Conditional inactivation of $\beta$-catenin in skeletal progenitors, or inactivation of Wnt10b or Lrp5 (a Wnt receptor), results in low bone mass (osteopenia) (Hartmann 2006). The $\beta$ catenin-TCF/LEF complex regulates the expression of the osteogenesis genes, RUNX2, RANK ligand, osteoprotegerin, and osteocalcin (Dong et al. 2006; Glass et al. 2005; Spencer et al. 2006). Similarly, SPARC-null mice develop osteopenia that becomes more severe as the animals age (Delany et al. 2000). Consistently, both MSCs from SPARCnull bone marrow and preadipocytes from SPARC-null WAT, show an increased tendency to form adipocytes and a decreased tendency to form osteoblasts (Delany et al. 2003). Therefore, SPARC could regulate osteoblast formation, maturation, and survival through the $\mathrm{Wnt} / \beta$-catenin pathway.
As shown in Fig. 1, we also demonstrated that SPARC activates integrin-linked kinase (ILK), which in turn phosphorylates and inhibits GSK3 $\beta$ activity and leads to the accumulation of $\beta$-catenin in both the cytosol and the nucleus (Nie and Sage 2009). Which protein and/or protein complex is downstream of SPARC that affects the activation of ILK? SPARC interacts not only with ECM components, but also with integrins and growth factors; therefore, a possible pathway is the activation of ILK through an interaction of SPARC with integrins. SPARC interacts with $\beta 1$ integrin and subsequently enhances the activation of ILK in lens epithelial cells (Weaver et al. 2008). In preadipocytes, SPARC-mimicking peptides bind to $\alpha 5 \beta 1$ integrin (Nie et al. 2008). SPARC enhances the activity of ILK at an early stage of adipocyte differentiation, and an ILK-specific inhibitor partially blocks the inhibitory effects

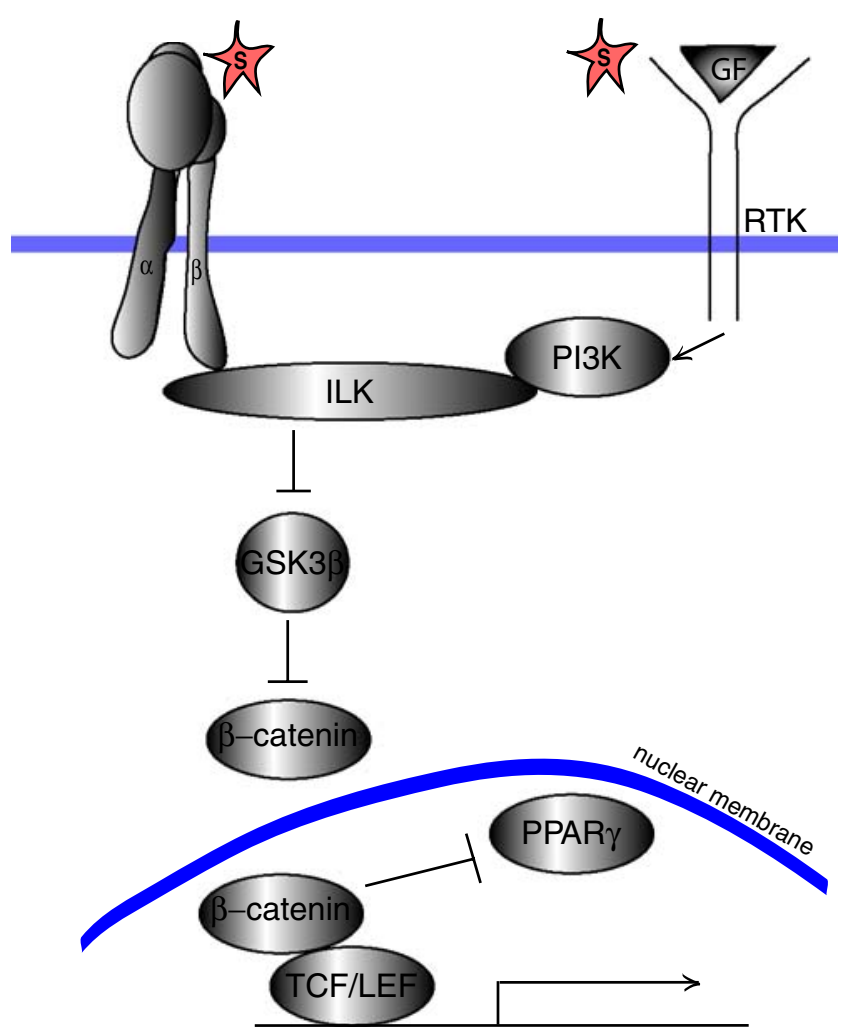

Fig. 1 SPARC $(S$, in red star) inhibits adipogenesis by its enhancement of $\beta$-catenin signaling. SPARC activates ILK, which in turn phosphorylates GSK- $3 \beta$ and inhibits its activity. GSK- $3 \beta$ activity is required for ubiquitin-mediated degradation of cytosolic $\beta$-catenin. Inhibition of GSK-3 $\beta$ activity results in the accumulation of $\beta$ catenin, which can translocate to the nucleus. In the nucleus, $\beta$-catenin can inhibit the activity of PPAR $\gamma$, activate TCF/LEF transcripotion factors, and regulate the expressions of many genes including those encoding growth factors and ECM proteins. SPARC could activate ILK through an interaction with integrins or with receptor tyrosine kinases (receptors of growth factors). S, SPARC; GF, growth factors; RTK, receptor tyrosine kinase; PI3K, Phosphoinositide-3 kinase; $\alpha$ and $\beta, \alpha$ and $\beta$ subunits of integrin; TCF/LEF, T-cell factor/lymphoidenhancing factor 
of SPARC (Nie and Sage 2009). ILK can be activated by an interaction with the cytoplasmic tail of $\beta 1 / \beta 3$ integrins (Oloumi et al. 2004); thus SPARC might enhance ILK activity through $\beta 1 / \beta 3$ integrins. Moreover, SPARC partially preserves cell adhesion to ECM during an early stage of adipogenesis (Nie and Sage 2009). In the absence of SPARC, preadipocytes partially detach, focal adhesion complexes are lost, focal adhesion kinase (FAK) and ILK activity are decreased, and the ECM is changed from a FNenriched matrix to a LN-enriched matrix. The partial detachment from FN-enriched ECM is crucial to allow cells to retract and for lipid to accumulate. SPARC might interfere with the mechanosensor function of integrin(s) and inhibit both outside-in and inside-out signaling of this receptor. In addition, the FN-ECM matrix is reorganized, and possibly cleaved, during an early stage of adipogenesis (Selvarajan et al. 2001). The changes in the interaction of $\mathrm{FN}$ with its cognate integrin might lead to conformational changes of the receptor and cell rounding or contraction. SPARC could interact with integrin to maintain the activity of ILK and FAK in preadipocytes (Fig. 2, state 4). Consequently, ILK activity would preserve the linkage among ECM compo-

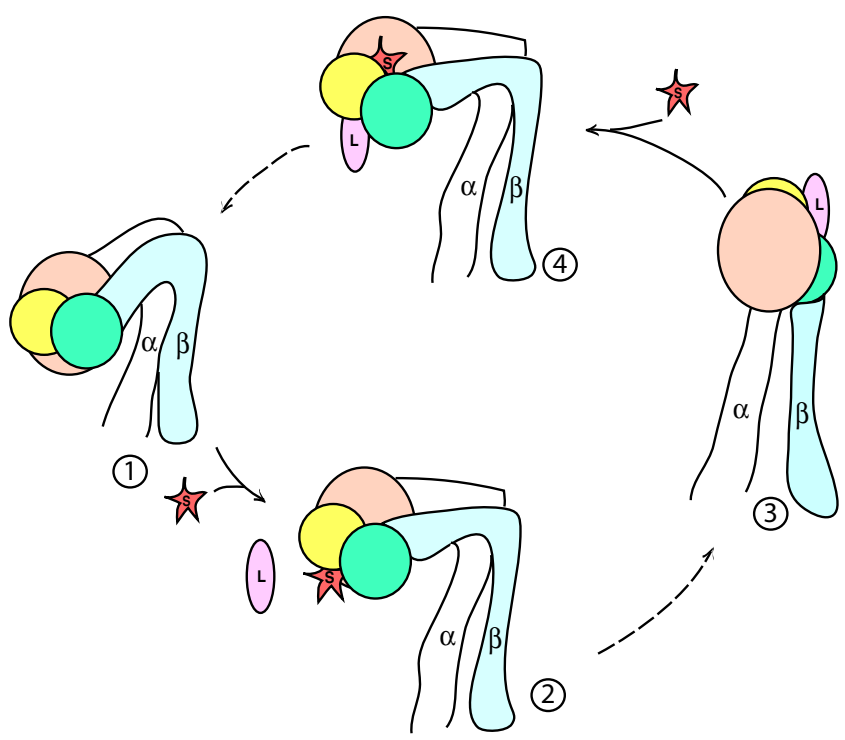

Fig. 2 A model showing how SPARC ( $S$, in red star) can interfere with integrin signaling. 1) The inactive state of an integrin. 2) During the adhesion process, SPARC competes with an integrin ligand $(L)$ for its binding site, and prevents the conformational change of the integrin to active state (dashed arrow). Therefore, SPARC inhibits the formation of focal adhesion and outside-in signaling. 3) ligandbinding (active) state of integrin. 4) SPARC slow down cell deadhesion. During inside-out signaling and subsequent deadhesion process, SPARC interacts with integrin and prevent the conformational change of integrin to state 1 (dashed arrow). Thus, SPARC preserve focal adhesions and inhibits inside-out signaling. We currently cannot predict the binding sites of SPARC on integrin in either state 2 or 4 . L, ligand of integrin; S, SPARC; $\alpha$ and $\beta, \alpha$ and $\beta$ subunits of integrin; pink circle, $\beta$-propeller domain of integrin $\alpha$ subunit; yellow circle, I domain of integrin $\alpha$ subunit; green circle, I-like domain of integrin $\beta$ subunit nents, integrins, and the actin cytoskeleton, with subsequent preservation of focal adhesion complexes. Consistent with this proposal, SPARC also induces the phosphorylation and activation of FAK in glioma cells (Shi et al. 2007).

SPARC might retard the deadhesion process during an early stage of adipocyte differentiation by its interference with integrin-mediated signaling. The adhesive effect of SPARC in adipogenesis is not inconsistent with the anti-adhesive function of SPARC in endothelial and glioma cells (Rempel et al. 2001; Sage et al. 1989). During the process of adhesion, SPARC might compete with certain ECM proteins for their binding sites on integrins (Fig. 2, state 2). SPARC could in fact act as a fine tuner of integrin signaling.

Alternatively, SPARC could activate ILK by its interference with growth-factor signaling (Fig. 1). Insulin, platelet-derived growth factor (PDGF), and other growth factors can stimulate ILK activity through phosphoinositide 3-kinases (Dedhar et al. 1999; Delcommenne et al. 1998). SPARC is involved in growth factor signaling, e.g., it binds to PDGF and vascular endothelial growth factor (VEGF), and inhibits the binding of these growth factors to their cognate receptors (Battegay et al. 1994; Kupprion et al. 1998; Nozaki et al. 2006; Raines et al. 1992). Together with integrins, growth factors also regulate adipogenesis. However, further investigation is required to ascertain whether SPARC activates ILK by signaling via growth-factor.

During adipogenesis, $\mathrm{Wnt} / \beta$-catenin signaling leads to the remodeling of ECM and changes in the expression of integrin and ECM components. Although it is not clear whether $\mathrm{Wnt} / \beta$-catenin directly regulates the expression of integrins or any ECM components, our evidence indicates that $\beta$-catenin-mediated signaling is involved in the regulation of integrin expression. $\mathrm{LiCl}$, a strong inducer of $\beta$-catenin signaling, significantly inhibited the expression of $\alpha 6$ integrin. ILK activity, which also enhances $\beta$-catenin accumulation, is required for SPARC to inhibit the expression of $\alpha 6$ integrin. Because $\mathrm{Wnt} / \beta$-catenin has been shown to regulate ECM remodeling and expression through PPAR $\gamma$ (Liu et al. 2006), SPARC might therefore affect ECM composition through $\beta$-catenin-mediated signaling.

\section{Angiogenesis}

WAT is highly vascularized, and each adipocyte is nourished by an extensive vasculature. Adipogenesis is associated with, and in most cases dependent on, angiogenesis. Fetal adipocyte development is spatially and temporally related to the development of microvessels. Arteriolar development precedes adipocyte differentiation in internal WAT depots (Hausman and Richardson 2004). Interestingly, adipocytes and endothelial cells might share a common progenitor (Planat-Benard et al. 2004). Adipose 
progenitor cells reside in the adipose vasculature as demonstrated in PPAR $\gamma$-tet transactivator knock-in mice (Tang et al. 2008; Traktuev et al. 2008). Moreover, blockade of VEGF signaling can inhibit WAT formation in vivo (Fukumura et al. 2003), whereas depletion of adipose vasculature results in WAT resorption (Kolonin et al. 2004).

SPARC is involved in the regulation of angiogenesis. Proteolytic fragments of SPARC have different effects on angiogenesis, and the function of SPARC is cell/tissue/ condition-specific and concentration-dependent. The effect of SPARC depends on the exposed epitope and its conformation, and on the availability of binding partners/ targets. SPARC inhibits endothelial cell proliferation and increases the permeability of endothelial monolayers in vitro. SPARC peptides 2.1 (in the follistatin domain) and 4.2 (in the C-terminal $\mathrm{Ca}^{++}$binding EF-hand) exert inhibitory effects on cell proliferation (Jendraschak and Sage 1996). SPARC also interacts with PDGF and interferes with PDGF signaling that indirectly promotes angiogenesis (Raines et al. 1992). SPARC contains a copper-binding motif (K)GHK that stimulates endothelial cell proliferation and angiogenesis in vivo and in vitro (Lane et al. 1994). There is a heightened neovascular response in sponge implants in SPARC-null, compared to wild-type mice. (Bradshaw et al. 2001)

In WATs, the driving forces in angiogenesis are hypoxia and signals from the sympathetic nervous system (Cao 2007). Both conditions activate VEGF signaling and downregulate endogenous inhibitors, such as thrombospondin 1. VEGF-A plays a central role in the angiogenesis of WATs. VEGF-A signaling is balanced by VEGFR-1 and -2: VEGFR-1 mediates an inhibitory signal, and VEGFR-2, a stimulatory signal. SPARC binds to VEGF-A and inhibits the activation of VEGFR-1 but not that of VEGFR-2 in vitro (Kupprion et al. 1998). Consistent with these data, SPARC competes with VEGF-A for the binding and activation of VEGFR-1 and thereby enhances choroidal neovascularization (Nozaki et al. 2006). Both adipose stromal cells and (pre) adipocytes produce VEGF-A. In WATs, SPARC might also limit the activation of VEGFR-1 by VEGF-A, and thereby promote angiogenesis, during adipogenesis.

\section{Conclusions}

1) SPARC inhibits adipogenesis and enhances osteoblastogenesis by its enhancement of the $\mathrm{Wnt} / \beta$-catenin pathway; 2 ) SPARC also inhibits adipogenesis through its regulation of collagen expression and deposition; 3) SPARC appears to drive preadipocytes from the status of growth arrest and therefore prevents terminal differentiation; 4) SPARC might inhibit adipogenesis through its regulation of adipose tissue angiogenesis. Further investigation is needed to uncover the mechanisms underlying the inhibitory effects of SPARC on adipogenesis in vivo. We also cannot exclude the possibility that SPARC affects lipid metabolism in other organs, e.g., brain, liver, and pancreas, and thereby affects lipid accumulation in WAT.

Open Access This article is distributed under the terms of the Creative Commons Attribution Noncommercial License which permits any noncommercial use, distribution, and reproduction in any medium, provided the original author(s) and source are credited.

\section{References}

Arango NA, Szotek PP, Manganaro TF, Oliva E, Donahoe PK, Teixeira J (2005) Conditional deletion of beta-catenin in the mesenchyme of the developing mouse uterus results in a switch to adipogenesis in the myometrium. Dev Biol 288:276-283

Ashrafi K, Chang FY, Watts JL, Fraser AG, Kamath RS, Ahringer J, Ruvkun G (2003) Genome-wide RNAi analysis of Caenorhabditis elegans fat regulatory genes. Nature 421:268-272

Barker TH, Baneyx G, Cardo-Vila M, Workman GA, Weaver M, Menon PM, Dedhar S, Rempel SA, Arap W, Pasqualini R, Vogel $\mathrm{V}$, Sage EH (2005) SPARC regulates extracellular matrix organization through its modulation of integrin-linked kinase activity. J Biol Chem 280:36483-36493

Battegay EJ, Rupp J, Iruela-Arispe L, Sage EH, Pech M (1994) PDGF-BB modulates endothelial proliferation and angiogenesis in vitro via PDGF beta-receptors. J Cell Biol 125:917-928

Bodine PV, Zhao W, Kharode YP, Bex FJ, Lambert AJ, Goad MB, Gaur T, Stein GS, Lian JB, Komm BS (2004) The Wnt antagonist secreted frizzled-related protein-1 is a negative regulator of trabecular bone formation in adult mice. Mol Endocrinol 18:1222-1237

Bornstein P, Sage EH (2002) Matricellular proteins: extracellular modulators of cell function. Curr Opin Cell Biol 14:608-616

Bradshaw AD, Reed MJ, Carbon JG, Pinney E, Brekken RA, Sage EH (2001) Increased fibrovascular invasion of subcutaneous polyvinyl alcohol sponges in SPARC-null mice. Wound Repair Regen 9:522-530

Bradshaw AD, Reed MJ, Sage EH (2002) SPARC-null mice exhibit accelerated cutaneous wound closure. J Histochem Cytochem 50:1-10

Bradshaw AD, Graves DC, Motamed K, Sage EH (2003a) SPARC-null mice exhibit increased adiposity without significant differences in overall body weight. Proc Natl Acad Sci U S A 100:6045-6050

Bradshaw AD, Puolakkainen P, Dasgupta J, Davidson JM, Wight TN, Helene Sage E (2003b) SPARC-null mice display abnormalities in the dermis characterized by decreased collagen fibril diameter and reduced tensile strength. J Invest Dermatol 120:949-955

Cao Y (2007) Angiogenesis modulates adipogenesis and obesity. J Clin Invest 117:2362-2368

Chavey C, Boucher J, Monthouel-Kartmann MN, Sage EH, CastanLaurell I, Valet P, Tartare-Deckert S, Van Obberghen E (2006) Regulation of secreted protein acidic and rich in cysteine during adipose conversion and adipose tissue hyperplasia. Obesity (Silver Spring) 14:1890-1897

Christodoulides C, Lagathu C, Sethi JK, Vidal-Puig A (2009) Adipogenesis and WNT signalling. Trends Endocrinol Metab 20:16-24

Chun TH, Hotary KB, Sabeh F, Saltiel AR, Allen ED, Weiss SJ (2006) A pericellular collagenase directs the 3-dimensional development of white adipose tissue. Cell 125:577-591

Colognato H, Winkelmann DA, Yurchenco PD (1999) Laminin polymerization induces a receptor-cytoskeleton network. J Cell Biol 145:619-631 
Dedhar S, Williams B, Hannigan G (1999) Integrin-linked kinase (ILK): a regulator of integrin and growth-factor signalling. Trends Cell Biol 9:319-323

Delany AM, Amling M, Priemel M, Howe C, Baron R, Canalis E (2000) Osteopenia and decreased bone formation in osteonectindeficient mice. J Clin Invest 105:915-923

Delany AM, Kalajzic I, Bradshaw AD, Sage EH, Canalis E (2003) Osteonectin-null mutation compromises osteoblast formation, maturation, and survival. Endocrinology 144:2588-2596

Delcommenne M, Tan C, Gray V, Rue L, Woodgett J, Dedhar S (1998) Phosphoinositide-3-OH kinase-dependent regulation of glycogen synthase kinase 3 and protein kinase B/AKT by the integrin-linked kinase. Proc Natl Acad Sci U S A 95:11211-11216

Dong YF, Soung do Y, Schwarz EM, O'Keefe RJ, Drissi H (2006) Wnt induction of chondrocyte hypertrophy through the Runx2 transcription factor. J Cell Physiol 208:77-86

Farmer SR (2005) Regulation of PPARgamma activity during adipogenesis. Int J Obes (Lond) 29(Suppl 1):S13-16

Fukumura D, Ushiyama A, Duda DG, Xu L, Tam J, Krishna V, Chatterjee K, Garkavtsev I, Jain RK (2003) Paracrine regulation of angiogenesis and adipocyte differentiation during in vivo adipogenesis. Circ Res 93:e88-97

Girnun GD, Smith WM, Drori S, Sarraf P, Mueller E, Eng C, Nambiar P, Rosenberg DW, Bronson RT, Edelmann W, Kucherlapati R, Gonzalez FJ, Spiegelman BM (2002) APC-dependent suppression of colon carcinogenesis by PPARgamma. Proc Natl Acad Sci U S A 99:13771-13776

Glass DA 2nd, Bialek P, Ahn JD, Starbuck M, Patel MS, Clevers H, Taketo MM, Long F, McMahon AP, Lang RA, Karsenty G (2005) Canonical Wnt signaling in differentiated osteoblasts controls osteoclast differentiation. Dev Cell 8:751-764

Glass DA 2nd, Karsenty G (2006) Canonical Wnt signaling in osteoblasts is required for osteoclast differentiation. Ann N Y Acad Sci 1068:117-130

Gregoire FM, Smas CM, Sul HS (1998) Understanding adipocyte differentiation. Physiol Rev 78:783-809

Hartmann C (2006) A Wnt canon orchestrating osteoblastogenesis. Trends Cell Biol 16:151-158

Hausman GJ, Richardson RL (2004) Adipose tissue angiogenesis. J Anim Sci 82:925-934

Hohenester E, Sasaki T, Giudici C, Farndale RW, Bachinger HP (2008) Structural basis of sequence-specific collagen recognition by SPARC. Proc Natl Acad Sci U S A 105:18273-18277

Jendraschak E, Sage EH (1996) Regulation of angiogenesis by SPARC and angiostatin: implications for tumor cell biology. Semin Cancer Biol 7:139-146

Kang S, Bennett CN, Gerin I, Rapp LA, Hankenson KD, Macdougald OA (2007) Wnt signaling stimulates osteoblastogenesis of mesenchymal precursors by suppressing CCAAT/enhancer-binding protein alpha and peroxisome proliferator-activated receptor gamma. J Biol Chem 282:14515-14524

Kawaguchi N, Toriyama K, Nicodemou-Lena E, Inou K, Torii S, Kitagawa Y (1998) De novo adipogenesis in mice at the site of injection of basement membrane and basic fibroblast growth factor. Proc Natl Acad Sci U S A 95:1062-1066

Kennell JA, MacDougald OA (2005) Wnt signaling inhibits adipogenesis through beta-catenin-dependent and -independent mechanisms. J Biol Chem 280:24004-24010

Keophiphath M, Achard V, Henegar C, Rouault C, Clement K, Lacasa D (2009) Macrophage-secreted factors promote a profibrotic phenotype in human preadipocytes. Mol Endocrinol $23: 11-24$

Khan T, Muise ES, Iyengar P, Wang ZV, Chandalia M, Abate N, Zhang BB, Bonaldo P, Chua S, Scherer PE (2009) Metabolic dysregulation and adipose tissue fibrosis: role of collagen VI. Mol Cell Biol 29:1575-1591
Kolonin MG, Saha PK, Chan L, Pasqualini R, Arap W (2004) Reversal of obesity by targeted ablation of adipose tissue. Nat Med 10:625-632

Kuo HJ, Maslen CL, Keene DR, Glanville RW (1997) Type VI collagen anchors endothelial basement membranes by interacting with type IV collagen. J Biol Chem 272:26522-26529

Kupprion C, Motamed K, Sage EH (1998) SPARC (BM-40, osteonectin) inhibits the mitogenic effect of vascular endothelial growth factor on microvascular endothelial cells. J Biol Chem 273:29635-29640

Lane TF, Iruela-Arispe ML, Johnson RS, Sage EH (1994) SPARC is a source of copper-binding peptides that stimulate angiogenesis. J Cell Biol 125:929-943

Liu J, DeYoung SM, Zhang M, Cheng A, Saltiel AR (2005) Changes in integrin expression during adipocyte differentiation. Cell Metab 2:165-177

Liu J, Wang H, Zuo Y, Farmer SR (2006) Functional interaction between peroxisome proliferator-activated receptor gamma and beta-catenin. Mol Cell Biol 26:5827-5837

Longo KA, Wright WS, Kang S, Gerin I, Chiang SH, Lucas PC, Opp MR, MacDougald OA (2004) Wnt10b inhibits development of white and brown adipose tissues. J Biol Chem 279:35503-35509

Martinek N, Shahab J, Saathoff M, Ringuette M (2008) Haemocytederived SPARC is required for collagen-IV-dependent stability of basal laminae in Drosophila embryos. J Cell Sci 121:1671-1680

Maurer P, Hohenadl C, Hohenester E, Gohring W, Timpl R, Engel J (1995) The C-terminal portion of BM-40 (SPARC/osteonectin) is an autonomously folding and crystallisable domain that binds calcium and collagen IV. J Mol Biol 253:347-357

Minamitani T, Ikuta T, Saito Y, Takebe G, Sato M, Sawa H, Nishimura T, Nakamura F, Takahashi K, Ariga H, Matsumoto K (2004) Modulation of collagen fibrillogenesis by tenascin-X and type VI collagen. Exp Cell Res 298:305-315

Moldes M, Zuo Y, Morrison RF, Silva D, Park BH, Liu J, Farmer SR (2003) Peroxisome-proliferator-activated receptor gamma suppresses Wnt/beta-catenin signalling during adipogenesis. Biochem J 376:607-613

Nie J, Chang B, Traktuev DO, Sun J, March K, Chan L, Sage EH, Pasqualini R, Arap W, Kolonin MG (2008) IFATS collection: Combinatorial peptides identify alpha5beta1 integrin as a receptor for the matricellular protein SPARC on adipose stromal cells. Stem Cells 26:2735-2745

Nie J, Sage EH (2009) SPARC inhibits adipogenesis by its enhancement of beta-catenin signaling. J Biol Chem 284:1279-1290

Nozaki M, Sakurai E, Raisler BJ, Baffi JZ, Witta J, Ogura Y, Brekken RA, Sage EH, Ambati BK, Ambati J (2006) Loss of SPARCmediated VEGFR-1 suppression after injury reveals a novel antiangiogenic activity of VEGF-A. J Clin Invest 116:422-429

O'Connor KC, Song H, Rosenzweig N, Jansen DA (2003) Extracellular matrix substrata alter adipocyte yield and lipogenesis in primary cultures of stromal-vascular cells from human adipose. Biotechnol Lett 25:1967-1972

Oloumi A, McPhee T, Dedhar S (2004) Regulation of E-cadherin expression and beta-catenin/Tcf transcriptional activity by the integrin-linked kinase. Biochim Biophys Acta 1691:1-15

Pendas AM, Folgueras AR, Llano E, Caterina J, Frerard F, Rodriguez F, Astudillo A, Noel A, Birkedal-Hansen H, Lopez-Otin C (2004) Diet-induced obesity and reduced skin cancer susceptibility in matrix metalloproteinase 19-deficient mice. Mol Cell Biol 24:5304-5313

Planat-Benard V, Silvestre JS, Cousin B, Andre M, Nibbelink M, Tamarat R, Clergue M, Manneville C, Saillan-Barreau C, Duriez M, Tedgui A, Levy B, Penicaud L, Casteilla L (2004) Plasticity of human adipose lineage cells toward endothelial cells: physiological and therapeutic perspectives. Circulation 109:656-663

Raines EW, Lane TF, Iruela-Arispe ML, Ross R, Sage EH (1992) The extracellular glycoprotein SPARC interacts with platelet-derived 
growth factor (PDGF)-AB and $-\mathrm{BB}$ and inhibits the binding of PDGF to its receptors. Proc Natl Acad Sci U S A 89:1281-1285

Rempel SA, Golembieski WA, Fisher JL, Maile M, Nakeff A (2001) SPARC modulates cell growth, attachment and migration of U87 glioma cells on brain extracellular matrix proteins. J Neurooncol 53:149-160

Robert G, Gaggioli C, Bailet O, Chavey C, Abbe P, Aberdam E, Sabatie E, Cano A, Garcia de Herreros A, Ballotti R, TartareDeckert S (2006) SPARC represses E-cadherin and induces mesenchymal transition during melanoma development. Cancer Res 66:7516-7523

Rodriguez Fernandez JL, Ben-Ze'ev A (1989) Regulation of fibronectin, integrin and cytoskeleton expression in differentiating adipocytes: inhibition by extracellular matrix and polylysine. Differentiation 42:65-74

Rosen ED, Spiegelman BM (2000) Molecular regulation of adipogenesis. Annu Rev Cell Dev Biol 16:145-171

Ross SE, Hemati N, Longo KA, Bennett CN, Lucas PC, Erickson RL, MacDougald OA (2000) Inhibition of adipogenesis by Wnt signaling. Science 289:950-953

Sabatelli P, Bonaldo P, Lattanzi G, Braghetta P, Bergamin N, Capanni C, Mattioli E, Columbaro M, Ognibene A, Pepe G, Bertini E, Merlini L, Maraldi NM, Squarzoni S (2001) Collagen VI deficiency affects the organization of fibronectin in the extracellular matrix of cultured fibroblasts. Matrix Biol 20:475-486

Sage H, Vernon RB, Funk SE, Everitt EA, Angello J (1989) SPARC, a secreted protein associated with cellular proliferation, inhibits cell spreading in vitro and exhibits $\mathrm{Ca}+2$-dependent binding to the extracellular matrix. J Cell Biol 109:341-356

Selvarajan S, Lund LR, Takeuchi T, Craik CS, Werb Z (2001) A plasma kallikrein-dependent plasminogen cascade required for adipocyte differentiation. Nat Cell Biol 3:267-275

Shi Q, Bao S, Song L, Wu Q, Bigner DD, Hjelmeland AB, Rich JN (2007) Targeting SPARC expression decreases glioma cellular survival and invasion associated with reduced activities of FAK and ILK kinases. Oncogene 26:4084-4094

Spencer GJ, Utting JC, Etheridge SL, Arnett TR, Genever PG (2006) Wnt signalling in osteoblasts regulates expression of the receptor activator of NFkappaB ligand and inhibits osteoclastogenesis in vitro. J Cell Sci 119:1283-1296

Spiegelman BM, Ginty CA (1983) Fibronectin modulation of cell shape and lipogenic gene expression in 3T3-adipocytes. Cell 35:657-666

Takahashi M, Nagaretani H, Funahashi T, Nishizawa H, Maeda N, Kishida K, Kuriyama H, Shimomura I, Maeda K, Hotta K, Ouchi N, Kihara S, Nakamura T, Yamashita S, Matsuzawa Y (2001) The expression of SPARC in adipose tissue and its increased plasma concentration in patients with coronary artery disease. Obes Res 9:388-393

Tang W, Zeve D, Suh JM, Bosnakovski D, Kyba M, Hammer RE, Tallquist MD, Graff JM (2008) White fat progenitor cells reside in the adipose vasculature. Science 322:583-586

Tartare-Deckert S, Chavey C, Monthouel MN, Gautier N, Van Obberghen E (2001) The matricellular protein SPARC/osteonectin as a newly identified factor up-regulated in obesity. J Biol Chem 276:22231-22237

Traktuev DO, Merfeld-Clauss S, Li J, Kolonin M, Arap W, Pasqualini R, Johnstone BH, March KL (2008) A population of multipotent CD34-positive adipose stromal cells share pericyte and mesenchymal surface markers, reside in a periendothelial location, and stabilize endothelial networks. Circ Res 102:77-85

Weaver MS, Sage EH, Yan Q (2006) Absence of SPARC in lens epithelial cells results in altered adhesion and extracellular matrix production in vitro. J Cell Biochem 97:423-432

Weaver MS, Workman G, Sage EH (2008) The copper binding domain of SPARC mediates cell survival in vitro via interaction with integrin betal and activation of integrin-linked kinase. $\mathrm{J}$ Biol Chem 283:22826-22837

Wilsie LC, Chanchani S, Navaratna D, Orlando RA (2005) Cell surface heparan sulfate proteoglycans contribute to intracellular lipid accumulation in adipocytes. Lipids Health Dis 4:2 